Which brings us to the second point, namely, whether Rio et $a l^{1}$ are right in maintaining that in their case (new syndrome $v s$ FXS), the use of

Type and Contre-type: a questionable concept

\section{. Long time no see: the Type and Contre-type concept}

\author{
Giovanni Neri and Francesca Romana Di Raimo
}

European Journal of Human Genetics (2010) 18, 135-136; doi:10.1038/ejhg.2009.171; published online 21 October 2009

$\mathrm{I}^{\mathrm{n}}$ this issue of the Journal, Rio et $a l^{1}$ describe a new syndromic form of X-linked mental retardation (XLMR). The phenotype seems to be quite distinct, characterized by mild mental delay, peculiar facial traits, short stature and hypergonadotrophic hypogonadism. It is caused by a small Xq27.3-Xq28 duplication of $5.1 \mathrm{Mb}$, encompassing 28 genes, including FMR1 but not $M E C P 2$. Obligate carrier mothers were of normal intelligence, but presented with short stature and early menopause. One of them had a completely skewed inactivation of the duplicated X chromosome. Altogether, three out of five carriers had a completely skewed X inactivation. This new condition represents an important addition to the stillgrowing list of XLMR syndromes.

After praising the authors for an excellent clinical-molecular description of the affected family, there is an interesting aspect of this article that we would like to comment on. The authors present the new syndrome as the contre-type of the fragile X syndrome (FXS), noting that the duplicated $\mathrm{X}$ chromosome contains a double dose of the FMR1 gene. The concept of contre-type took shape in France during the early days of cytogenetics, but does not seem to have enjoyed much fortune and popularity. There are two points that we wish to address: (1) Does the concept have a biological meaning and is it tenable? (2) Given, but not granted, that the concept is tenable, can Rio et $a l^{1}$ rightly claim that their newly described syndrome is the contre-type of FXS?

To the best of our knowledge, the term contre-type was first used by Lejeune et al in $1964,{ }^{2}$ in the description of a case of partial

Giovanni Neri is at the Istituto di Genetica Medica, Universita Cattolica Del Sacro Cuore, Large F. Vito 1, Roma 00168, Italy. Tel: +39 06305 4449;

Fax: +3906 305 0031; E-mail: gneri@rm.unicatt.it monosomy of a small acrocentric chromosome. The authors assumed that it was the same chromosome as in Down's syndrome (DS) and that the clinical manifestations seen in the patient were the antithesis of DS. In 1966, Reisman et $a l^{3}$ described another case of partial monosomy 21 and coined the term 'antimongolism'. The same expression can also be found in Yunis' New Chromosomal Syndromes, ${ }^{4}$ whereas type et contre-type was used again by de Grouchy and Turleau in their Atlas des Maladies Chromosomique ${ }^{5}$ to underline the opposite phenotypic effects of trisomy and partial monosomy 21 .

The concept of type and contre-type was criticized from early on, for example, by Hamerton. ${ }^{6}$ On page 268 of volume II of his classical book Human Cytogenetics, with reference to the use of the term antimongolism, one reads ' ...there is little justification for this usage which implies first that these patients are the opposite of Down's syndrome and second that the chromosome involved is the same as that in Down's syndrome for which there is little evidence.' There is even lesser justification today, in light of what we know of the phenogenesis of chromosomal syndromes. Let us continue with the example of DS. The analysis of partial trisomies of chromosome 21 led to the concept of the DS critical region, according to which single phenotypic traits of DS could each be related to a single triplicated gene. Although the expression is still being used, the concept is hard to maintain, at least in its initial formulation, after accumulating evidence that virtually all segments of chromosome 21 contribute to the phenotype of DS.7 Moreover, one should bear in mind that not every gene on chromosome 21 is dosage sensitive, meaning that a triple dose does not necessarily imply an increased amount of its protein product (reviewed by Antonarakis et $a l^{8}$ ). the type/contre-type concept is justified. They contrast the short stature in the affected males of the family $v s$ tendency to tall stature in FXS. This is true, but one should also consider that the carrier mothers in the family are very short too, which could reflect a character independent of the duplication on the $\mathrm{X}$ chromosome. One patient is reported as having a small head ( $-1 \mathrm{SD})$, whereas the other two are normocephalic, in partial contrast to macrocephaly, usually seen in FXS. Actually, if the head circumference of the three affected males is related to their stature, as it should be, they are all relatively macrocephalic. Peripheral hypogonadism and consequent small testes are not in contrast to what we see in FXS, in which the phenomenon of macro-orchidism, although not well understood, is not related to a condition of hypergonadism. Similarly, small hands and feet, obesity and a pitched voice are not matched by opposite signs in FXS. Mild mental delay can be seen in contrast with moderate-to-severe delay in FXS. To be pedantic, the opposite of mild intellectual delay should be mild intellectual superiority. Although we concede that this point may be arguable, good speech development in the three affected males described by Rio et al ${ }^{1}$ is clearly related to their mild global delay. Indeed, FXS individuals, especially those with a mild delay, may have a fluent speech. Actually, a major drawback in making these comparisons lies in the fact that we compare a single family in which phenotypic variability can only be very limited, with a vast, clinically variable collection of FXS individuals. Every one of us, who has seen many of these, can point to that particular FXS patient who was short, with a relatively small head, normal testicular volume, mild delay and good speech, almost the contre-type of the classical FXS patient.

While considering the carrier females of the family, all of whom are reported to have premature ovarian failure (POF), Rio et al advance the hypothesis that this might be related to an excess of FMR1 mRNA, as it is in premutation carriers. However, the hypothesis is hardly tenable, given that POF is present in all, whereas only three of them have completely skewed inactivation of the $\mathrm{X}$ chromosome bearing the duplication. Therefore, it is impossible to argue for an increased production of FMR1 mRNA as a potential cause of POF, especially as the authors do not provide a measure of this parameter. Actually, lack of evidence that FMR1 is overexpressed in affected males and carrier females is, in our opinion, the major weakness of this otherwise 
excellent work. Overexpression of FMR1, if demonstrated, could be related not only to POF but also to an increased risk of the affected males to develop tremor ataxia syndrome.

With regard to the concept of type and contre-type, may it rest in peace

1 Rio M, Malan V, Boissel S et al: Familial interstitial Xq27.3q28 duplication encompassing the
FMR1 gene but not the MECP2 gene causes a new syndromic mental retardation condition. Eur J Hum Genet 2009; E-pub ahead of print 21 October 2009, doi:10.1038/ejhg.2009.159.

2 Lejeune J, Berger R, Réthoré M-O et al: Monosomie partielle pour un petit acrocentrique. Compt Rend 1964; 259: 4187-4189.

3 Reisman LE, Kasahara S, Chung C-Y, Darnell A, Hall B: Anti-mongolism. Studies in an infant with a partial monosomy od the 21 chromosome. Lancet 1966; I: 394-397.

4 Gorlin RJ: Classical chromosome disorders; in Yunis JJ (ed): New Chromosomal Syndromes. New York: Academic Press, 1977, p 80.
5 de Grouchy J, Turleau C: Atlas de Maladies Chromosomiques. Paris: Expansion Scientifique, 1977, p 251.

6 Hamerton JL: Human Cytogenetics, Vol II New York: Academic Press, 1971; p 268.

7 Korenberg JR, Chen XN, Schipper R et al: Down syndrome phenotypes: the consequences of chromosomal imbalance. Proc Nat Acad Sci USA 1994; 91: 4997-5001.

8 Antonarakis SE, Lyle R, Dermitzakis ET, Reymond A, Deutsch S: Chromosome 21 and Down syndrome: From genomics to pathophysiology. Nature Rev Genet 2004; 5: 725-738. 